however, may be a consequence either of a difference of alimentation or of the rate at which the ice is moving. Thus long and careful observations are necessary of the latter, of the nature of the advance or retreat, and of other matters, before sufficient data can be obtained to allow of the results obtained in different regions being compared, and their bearing on questions of general meteorology ascertained, but the investigation now begun in the vast northern mountain barrier of Hindustan must ultimately prove to be highly valuable.

T. G. BONNEY.

TIDAL INVESTIGATIONS IN CANADA.

THERE are few countries which possess so large an extent of navigable land-locked waters as does Canada. In such situations the tidal currents are apt to assume great importance, and the prediction of the tides is a task of great difficulty. The Canadian Government has naturally paid much attention to this complex subject, and they are fortunate in having so able an officer as $\mathrm{Mr}$. W. Bell Dawson to place in charge of the operations.

In a paper on "The Currents of the Belle Isle Strait " (Government Printing Office, Ottawa, I907), Mr. Dawson gives an account of the investigations carried out in the seasons of 1894 and of 1906 . The run of the tide in the strait in places is sometimes apparently capricious, but $\mathrm{Mr}$. Dawson shows that in many cases the abnormalities become explicable when properly examined. The results should prove of much value to mariners.

Mr. Dawson has also contributed a paper on "Variations in the Leading Features of the Tide in Different Regions" to the Royal Astronomical Society of Canada (July-August).

It is obvious that in the vast tract of navigable Canadian waters, the cost would be prohibitive of erecting tide-gauges at all the places at which tidetables are wanted. Hence the calculation of the tides by reference to neighbouring harbours becomes a matter of necessity. It is a subject to which $\mathrm{Mr}$. Dawson has already paid much attention. The ordinary rough rule is to multiply the range of tide at the port of reference by a constant factor, and to apply a constant correction to the times of high and low water. But such a simple rule often leads to enormous errors of prediction. Now Mr. Dawson shows that this factor and correction of time should not be regarded as constant, but should be taken as variable with the position of the moon.

The three points in which the position of the moon is influential are phase, declination, and parallax. These undergo variations in months of slightly different lengths, called the synodic, the tropical, and the anomalistic months. The corrections should be dependent on all these three periods, and thus they acquire a considerable amount of complexity. The most interesting point in Mr. Dawson's investigation is that he finds that, in some cases, it is one of the three factors which is dominant, and elsewhere it is another. So much is this the case that it is often possible to omit all corrections except those which are periodic in one of the three months. The determination of the dominant factor appears to be empirical, and no physical explanation is assigned for this curious conclusion. May we not suspect that when one or two of the monthly variabilities in the corrections are evanescent as regards time and height of high and low water, they are really affecting the tidal currents?

In any case these partially empirical corrections are found to be satisfactory in providing fairly trustworthy tide-tables, by reference to ports where there are tide-gauges and directly computed tide-tables.

G. H. D.

\section{EDUCATION AND RESEARCH IN INDIA.}

THE battle between those who believe the sole duty of our professors in universities, colleges and other high educational institutions is to teach, and the best professor one who devotes the whole of his time to teaching, and those who believe that the highest and most fertile kind of teaching is that carried on by a professor who is an investigator as well as a teacher, has been fought out on many occasions and in many places.

Fortunately the latter view in late years has largely prevailed over the former, though the battle has still to be actively carried on in many places. The universities of Europe, at all events those which are the most progressive and of greatest importance, have accepted the fact that in the selection of their professors they must now take only such men as have given distinct proof of capacity for original work in one or other of the great departments of knowledge, and who may be expected to continue their original researches at every possible opportunity.

Unfortunately, in England this spirit has not always been acted on, and the condition of a good many of the institutions devuted to the highest culture is in the matter of research most unsatisfactory, and compares most unfavourably with institutions of similar grade on the Continent.

Nor, indeed, is this lack of original work in England confined to what may be called centres of the highest intellectual activity, but it largely pervades educational and technical institutions of all grades, and it is stated that in many cases where the management of such institutions is in the hands of committees, whose members are distinguished mainly by their success in trade, original research on the part of the staff is practically barred, and, if a professor or teacher is known to be an enthusiastic investigator, he is at once considered to be one who is not doing full justice to the students entrusted to his charge.

It is to be hoped that such instances will become more and more rare as the proper functions of a teacher are better understood, and it is for our universities, and for all educational institutions more or less controlled or influenced by Government, to take the lead in this matter and to insist on the inseparability of research from the highest branches of teaching.

An opportunity of taking such a stand and of doing an almost incalculable amount of good to the higher teaching of a country now appears to lie in the hands of the Indian Government. For a good many years India may be said to have been suffering from an educational unrest, for it was understood by all those who had studied the subject that Indian education had been working on unfortunate lines. Lord Curzon, during the time he was Viceroy, was the first who boldly faced a very difficult problem, and under his direction Indian education was placed upon a much more satisfactory basis. The changes brought about by Lord Curzon's action were very numerous; primary education was largely extended and made more practical, female education was fostered in every possible way, secondary education was also improved, and, lastly, university education was dealt with. Under a new Indian University Act a complete set of new regulations has been prepared, and speaking generally of these regulations it may be said that they have aimed at, first, the influencing of the characters of the students in the colleges and high schools, and, secondly, at securing a practical rather than a book knowledge of the subjects dealt with.

It may also be nientioned that, in cases where a science is being studied, the regulations require each student to have had personal practical instruction 
and so far as possible to be practically examined. In the case of the higher degrees, such as D.Lit. and D.Sc., original work on the part of the student is an essential preliminary to his getting the degree, and even with lower degrees provision is made for anyone showing any practical originality to be excused a certain part of the usual theoretical book work.

It is, of course, understood that these regulations will require a stronger professorial staff to man the colleges of the universities than if merely theoretical instruction had to be given. A good many of the colleges attached to the Indian universities, indeed all the largest and most important, are directly manayed by the Indian Government, and it is on the action of this body that to a large extent the effective working of the new Indian University Act will depend. The colleges must be dealt with liberally in the matter of staff, or the Act will be inoperative, for if Government colleges, with the resources of Government behind them, do not take the lead, it is useless to expect any others to work up to the desired standard.

An important article in the influential Indian newspaper, The Pioneer, of October $3 \mathrm{I}$, describes the condition of things in the Indian colleges as being rather critical at the present time. The following is an cxtract from the article:

"The first commotion created by Lord Curzon's measures of University Reform has died away long ago; but it must not be overlooked that the work merely initiated by new Acts and sets of Regulations has yet to be actually done, and that rather momentous issues depend on the spirit in which it is done. We are reminded of this by certain papers of a controversial nature, written by members of the Bengal Educational Service, into which we have been allowed an insight. The controversy on the face of it would appear to be one of purely local interest, turning on the question whether the present professorial staff of the Presidency College, Calcutta, is adequate to the demands made on College teaching by the new Regulations of the University. But a perusal of the papers shows that matters of deep importance-the future of all teaching, learning and research in this country are involved in the discussion. An educational officer specially deputed by Government to report on the state and requirements of the Presidency College maintains that if the College is to satisfy the new demands on teaching the Science Professors must at once largely curtail the research work in which they have been indulging in the past, and another officer, closely connected with the College, in endorsing these remarks, tells us that research in the Presidency College has of late become something of a bogey,' even demonstrators and assistants being 'involved in researches.' This, he assures us, has led to neglect of pure teaching, and the first measure demanded by the new era of higher education is that the entire staff, from the senior professors downwards, should put aside their researches which, as far as the interests of the College are concerned, are not only useless but positively injurious. Against these views the Science Professors maintain that they and their subordinates have not neglected, and do not mean to neglect, 'teaching,' but that research and training in the methods of research constitutes an important, in fact essential, element in all higher stages of instruction. It is evident that what is being discussed here is no less than the entire future character of the upper sections of our large Colleges and the standing of their Professors. Is it to be a principle recognised, and eventually to be enforced, that Professors lecturing to B.A., B.Sc., M.A., and M.Sc. classes must limit themselves to mere teaching, whereby the antagonists of research evidently understand the assiduous inculcation into the minds of students of established facts and theories with the special aim of training the recipients of knowledge rapidly to reproduce in writing at examination time as much of the matter committed to memory as they can possibly manage; or should higher teachers in our Colleges be encouraged, possibly definitely expected, to combine with such teach-

$$
\text { NO. I 992, VOL. } 77 \text { ? }
$$

ing efforts to rouse in their students the appetite and capacity for original work and research? The latter alternative, of course, would imply that the men to whom higher teaching is entrusted should not be mere schoolmasters, but should themselves take some active part in the advancement of knowledge and learning."

It is greatly to be hoped that the Indian Government will seize the opportunity and properly strengtnen all its colleges with professors who are investigators as well as teachers, and thus at once set a proper standard for the highest education in India. On the action taken now the future of Indian education largely depends, and on the giving of a proper education to the future leaders of the Indian community will depend the peace, progress and prosperity of our Indian Empire.

\section{NOTES.}

WE understand that Sir Norman Lockyer has been in communication with the French Minister of Public Instruction with the view of securing active support for the science section of the Franco-British Exhibition to be held in London this year. The Minister has referred the matter to the Paris Academy of Sciences, and it is hoped that the result will be a satisfactory and substantial representation of scientific work in France at the forthcoming exhibition. The various divisions of the British section of the exhibition were described in Nature of November 2 I, 1907 (p. 67). This section was instituted with the assistance of the British Science Guild, and is in the course of organisation by a committee including leading representatives of all branches of pure science. The British committee has been given an area of eleven thousand square feet, gratis, for the purpose of exhibiting apparatus, appliances, and results of scientific research. This free grant of space is equivalent to a gift of about $3000 l$, and in addition the committee has been granted a sum of money in aid of the science section. The executive committee of the British side of the exhibition has thus provided a very favourable opportunity of exhibiting some of the achievements of scientific research and enlightening the general public as to the instruments or methods employed. It is the duty of the men of science of Great Britain to show appreciation of this generous treatment by assisting the committee in every way within their power to make the science section of the exhibition instructive, illuminating, and inspiring to the many thousands who will visit it.

Sir George Darwin, K.C.B., F.R.S., has been elected a foreign correspondant of the Paris Academy of Sciences in the section of geography and navigation. Lord Brassey has also been elected a correspondant of the academy.

Prof. Raphael Meldola, F.R.S., past-president of the Chemical Society, has been elected president of the Society of Dyers and Colourists in succession to the late Sir W. H. Perkin.

IT is announced in Science that $\mathrm{Mr}$. Andrew Carnegie has added $400,000 \%$. to the endowment of the Carnegie Institution of Washington.

Sir Otro JAFFe, president of the Belfast Natural History and Philosophical Society, has taken preliminary steps to form a committee to honour the memory of Lord Kelvin by erecting a statue or other suitable memorial in his native city of Belfast.

WE regret to see the announcement of the death of Sir Alfred B. Garrod, F.R.S., in his eighty-ninth year. Dr. Garrod graduated as M.D. of the London University 